\title{
Heterogeneous Approaches for Cluster based Routing Protocol in Vehicular Ad Hoc Network (VANET)
}

\author{
D. Satyajeet \\ Research Scholar, CSE Department \\ G.H.Raisoni College of Engineering, \\ Nagpur, INDIA
}

\author{
A. R. Deshmukh \\ Research Scholar, ETC Department \\ G.H.Raisoni College of Engineering, \\ Nagpur, INDIA
}

\author{
S. S. Dorle \\ H.O.D., ETRX Department \\ G.H.Raisoni College of Engineering, \\ Nagpur, INDIA
}

\begin{abstract}
Vehicular Ad Hoc Network (VANET) has materialized as a major research area for the last decade. Since the vehicular network does not have stable infrastructure the main focus remains on networking part, which is divided into clusters using clustering techniques to increase scalability of the network. This paper is a survey on heterogeneous approaches for a cluster based routing protocol that is used to make stable topology of unsteady vehicular networks. Starting with a brief history and introduction of the vehicular communication we have investigated each and every aspect of various novel routing protocol proposed based on clustering in VANET. An overview of traditional cluster based routing protocol (CBRP) is presented at the beginning and the paper is concluded with discussion describing our views on the survey.
\end{abstract}

\section{General Terms}

S.......Source

D.......Destination

CH......Cluster Head

GN......Gateway Node

RSU.....Roadside Unit

HM......HELLO Message

UN......Undecided Node

MN......Member Node

QoS.....Quality of Service

ITJ.....Invite-to-Join

RTJ.....Request-to-Join

MEP......Member Packet

\section{Keywords}

Vehicular Ad Hoc Network, Vehicular Communications, Vehicular Routing Protocols, MANET, Cluster, Routing, Cluster based Routing Rrotocol (CBRP)

\section{INTRODUCTION}

The idea of VANET came into existence in 1970s as Electronic Route-Guidance System (ERGS) which was proposed by Dan A. Rosen et al, and is viewed as a stepping stone toward highway communication and control system [1]. The PROMETHEUS (Program for European Traffic with Highest Efficiency and Unprecedented
Safety) framework was initiated and launched in Europe in 1988, in which research and development activities in the area of information technology and mobile communications for motor vehicles were carried out. In 1997 and 2000 some remarkable milestone and major paradigm shifts were seen in USA and in Japan, with impressive results on cooperative autonomous driving demonstration. From 1998 to 2005 the focus was shifted to cooperative active safety. The communication between vehicles in the early days of VANET was operated in $\mathrm{kHz}$. But from recent years we have advance radio equipment with which we can communicate faster and better. Devices are equipped with various wireless media access control (MAC) standards like IEEE 802.11, Long Term Evolution (LTE) or Worldwide Interoperability for Microwave Access (WiMax). The IEEE $802.11 \mathrm{p}$ standard is latest in this list, however, a short-range communication can also be used as Personal Area Networks using Bluetooth technology for Wireless Access in Vehicular Environments (WAVE) protocol stack [2].

The concept of VANET is very simple, it consists of a large web of vehicles and a wireless local area network (WLAN) technology that connects all these vehicles together to make communication possible. In VANET, the On Board Units (OBUs) are fitted in each vehicle that serves as a transmitter and receiver unit. The communication either occurs directly between vehicle to vehicle (V2V) or via a base station unit like Road Side Unit (RSU) called as a vehicle to infrastructure (V2I). VANET forms a dynamic and unsteady topology because of its high speed vehicle mobility and requires real time data packet transmission [3]. To transfer data packets successfully, routing plays an important role. VANET uses many routing protocols, one of them is Cluster Based Routing Protocol (CBRP), which works efficiently in unstable network topology. But the traditional clustering technique lacks in providing Quality of Service (QoS) and makes it hard to achieve the stable network. Hence the traditional protocol is modified in so many different ways and analyzed on different simulators on various parameters to make clustering technique effective in unstable VANET topology. This paper is a survey of such clustering routing protocols used in VANET that were proposed to make the traditional clustering technique effective.

The paper is organized in different sections, section 2 describes the categorization of VANET protocols, section 3 will give highlights on working of clustering technique. A detailed overview of clustering protocols that are proposed specially for VANET is presented 


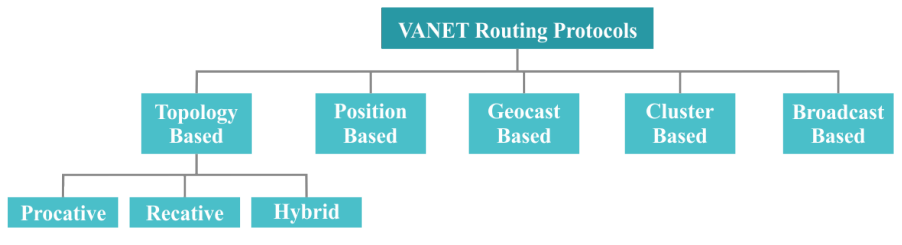

Fig. 1. Categorization of VANET Routing Protocol.

in section 4. In section 5 we discussed our views in brief, followed by conclusion in section 6 .

\section{ROUTING PROTOCOLS FOR VANET}

Routing is an important part for any network, numerous routing protocols are designed for VANET to solve different purpose. The categorization of different VANET routing protocols is shown in Fig.1 [4], [5]. Protocol based on this categorization were studied, implemented and analysis is made on various performance parameter. The traces of first Cluster Based Routing Protocol in MANET can be found in [6] and [7]. Since then, there have been many versions of cluster based routing protocol were proposed. In the section IV we will be discussing such diverse versions of cluster based routing protocol.

\section{WORKING OF TRADITIONAL CBRP}

To discuss the working of cluster based protocol for VANET we discussed the essential work of Jiang et al., who introduced CBRP [7]. Clustering technique logically divides the vehicles into an overlapping (or non-overlapping in some cases) clusters that communicate with each other and increases the scalability of network. In [9] Krishna et al proposed an algorithm for creating a cluster and maintaining it at various networking event. Furthermore, Bevan Das et al proposed a protocol which has the capability of adapting and self-configuring the dynamic topology of MANET [8].

\subsection{Cluster Formation}

In CBRP the clusters cluster formation is adopted from [6], in which a network of disjoint wireless nodes is formed having network of overlapping clusters. Each cluster has their own cluster head $(\mathrm{CH})$, whose job is to communicate with other nodes within their cluster to maintain the cluster formation. Cluster formation in CBRP is the variation of simple "lowest ID" clustering algorithm in which the node with a lowest ID is elected as $\mathrm{CH}$ among its neighbors [7]. Each node maintains a neighbor table to form a cluster, and stores information such as neighbor?s IDs, role of node in a cluster ( $\mathrm{CH}$ or member node) and status of link (uni/bi-directional). At each broadcast of HELLO message (HM) the neighbor table is updated, these message are send at specific time interval. A HELLO message contains information about node state, neighbor table and cluster adjacency table [7]. The $\mathrm{CH}$ can communicate with $\mathrm{CH}$ of other cluster via a special node called as gateway node (GN).

\subsection{Node States}

A node in CBRP will always be in either undecided node (UN), cluster head $(\mathrm{CH})$ or member node $(\mathrm{MN})$ states. A node is in undecided state when it is not a part of any cluster, this occurs when the node is newly entered in the network. An UN receives HMs from the $\mathrm{CH}$ and if there is a bi-directional link between them it changes its state to member, and if there is no bi-directional link between them it itself declares cluster head forming a new cluster. If two $\mathrm{CH}$ have an overlapping radio range the one who has lower ID than other, becomes $\mathrm{CH}$ and the other $\mathrm{CH}$ has to become $\mathrm{MN}$. A node is a member node in cluster if it loses its $\mathrm{CH}$ position or its ID is higher other node. Otherwise it goes to undecided state (UN).

\subsection{Route Discovery}

During route discovery initially the source node (S), containing the ID and destination's address broadcast a route request package (RREQ) to CH-1 of its own cluster-1. Then $\mathrm{CH}-1$ (new source) sends a RREQ to gateway node (GN-1) who forward the packet to $\mathrm{CH}-2$ via gateway node $(\mathrm{GN}-2)$ of cluster-2. The RREQ contains the loose source route $[\mathrm{S}, \mathrm{C} 1, \mathrm{C} 2, \ldots, \mathrm{Ck}, \mathrm{D}]$, i.e. the list of node that it visited. As soon as the destination (D) receives RREQ it sends the route reply message (RREP) back to source (CH-1) using reversed loose source route [D,Ck, . . , C1, S] [7]. Whenever the $\mathrm{CH}-1$ receives RREP message it computes a strict source route, which consists the shortest path that connects those two clusters.

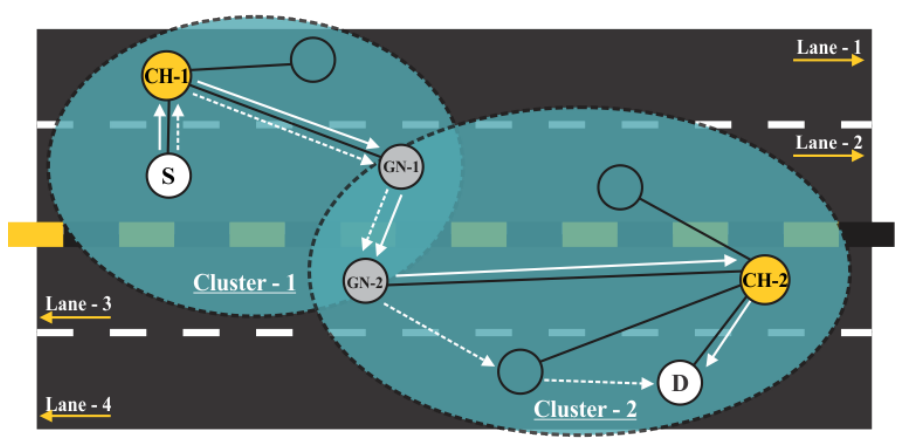

Fig. 2. Route Discovery between Source and Destination in CBRP.

In Fig. 2 two cluster are overlapping on each other having their own $\mathrm{CH}$. A loose source route (non-dashed white arrows) can be seen from source to destination via GN of both the clusters. And strict source route (dashed white arrows) can be seen from $\mathrm{S}$ to $\mathrm{D}$ which is the shortest path between sender and receiver.

\section{HETEROGENEOUS APPROACHES OF CBRP IN VANET}

This section will give a broad overview of different approaches of cluster-based routing proposed for VANET. Additionally, we present a table that give a brief idea of different techniques and approaches used in proposed protocol to produce effective results.

Starting with a novel protocol proposed by Santos, R.A et al in [10], which is a multi-hop routing and self-starting cluster based location routing (CBLR) [10] algorithm, based on CBRP [7]. The CH maintains a "Cluster Table" that consists of geographic locations and addresses of the MN and GN. The main difference between CBRP [7] and CBLR [10] is that, the $\mathrm{CH}$ of destination cluster creates a direct path between source and destination using the location reply packet (LREQ) once it received a broadcast route request packet (RREQ) from $\mathrm{CH}$ of source. CBLR shows less latency and reduced the number of packets in the buffer. CBLR [10] was again analyzed in [11], with two non-position based routing-algorithm AODV and DSR, and one position-based routing algorithm LORA. This time the scenario considered was having three lanes in which 
vehicles were moving in opposite direction of each other. Analysis shows that position-based routing algorithm gives better QoS in terms of packet delivery ratio and end-to-end delay as compared to non-position-based routing algorithm [11].

In [12] Jermy Blum et al, proposed a new cluster based routing algorithm called as Clustering for Open IVC Networks (COIN). In this clusters are formed between nodes travelling in same direction, rather than between both side traffic as seen in traditional clustering technique. This improves the stability of inter-vehicular communication (IVC) by increasing average cluster lifetime period by $192 \%$ and reduces the number of changes in cluster membership by $46 \%$ [12]. A sudden increase in signaling overhead degrades the performance of network and can affect the communication process. So a different approach is proposed in [13] by Hanan Saleet et al to minimize the signaling overhead caused due to increase in number of vehicles in network. The proposed Region-based Location Service Management Protocol (RLSMP) [13] creates a geographical cluster and restrict the location information within it, which increases scalability, gives guarantee of location awareness, has low signaling overhead and maximum channel utilization. But due to message aggregation a larger packet size is generated and bandwidth is wasted, this causes re-transmission and put impact on network throughput.

A novel and efficient broadcasting algorithm is presented in [14] using a cluster-based scheme that restricts rebroadcasting of data packets within the cluster. When a broadcast packet is arrived at $\mathrm{CH}$ it is rebroadcasted immediately. But when the broadcast packet is received by GN it sets its counter to ' 1 '. And checks whether it is from outside the cluster and counter value is not exceeding the threshold value, if yes then only it rebroadcast it else cancels the rebroadcast. This scheme increases the inter-cluster traffic propagation by delaying the traffic from outside the cluster. And hence it has high reachability and less delay when compared for different number of nodes and at different speed with different protocols. In [15] Seyed Amin Hosseini Seno et al proposed a modified version of CBRP [7] which is based on resource management services like Service Discovery (SD) and Service Advertisement (SA) [15]. A Service Access Table (SAT) [15] table is added in the CBRP [7] algorithm at each node to store all the available services. When a node shares a service, at first all the services are stores at node then it send these services to $\mathrm{CH}$. All the nodes in cluster sends updates to $\mathrm{CH}$ and $\mathrm{CH}$ modifies its SAT accordingly. The simulation result shows that as number of nodes increases the overhead of control message of proposed algorithm remains almost same after integrating SD I\& SA in CBRB [15].

Yang Xia et al proposed a novel two-layer hierarchical approach for cluster based routing to mitigate the impact of rapidly changing topology in VANET called as Hierarchical Cluster Based routing protocol (HCB) [16]. In HCB a two-layer hierarchical structure is created in such a way that, in layer- 1 all the nodes in network are present and communicate directly or indirectly (via base station) with each other. Some of the nodes are called as 'super nodes' and they act as CH in layer-1, layer-2 is made of only super nodes. The elected $\mathrm{CH}$ broadcast its own address and hop count to other nodes at regular intervals known as 'HEARTBEAT message' [16]. The UN join the cluster depending on sequence number and minimum hop distance to $\mathrm{CH}$ that resides in 'HEARTBEAT message'. Boundary Node (gateway node) [16] uses 'SCAN message' for topology discovery process, it sends partial information of topology to $\mathrm{CH}$, that are combined to form a complete topology map. The route in HCB is computed from HEARTBEAT messages using shortest path algorithms which has particular lifetime. Within this lifetime data packets has to be forwarded by the node to other nodes otherwise it has to be forwarded via a default route. Simulation result shows the reduced delay in topology discovery, better performance and high scalability in proposed HCB protocol [16].

Another novel approach to cluster based protocol in VANET proposed by Christine Shea et al in [17], whose simulation result shows high stability in clusters and superior performance of proposed algorithm. Using Affinity Propagation (AP) [17], a similarity function is created that provides with both mobility and node position. Each node sends responsibility and availability messages to its neighbors to form cluster with nodes that are only one-hop distance away. Due to this the cluster becomes more stable and the $\mathrm{CH}$ can hold its position for longer duration producing low rate of change in $\mathrm{CH}$ [17]. The work in [18] by utilizing the idea of clustering and handoff technique to make better performance of routing protocol in VANET. In Traffic Infrastructure Based Cluster Routing Protocol with Handoff (TIBCRPH) [18] a handoff metric is created to calculate the distance from node of one cluster to $\mathrm{CH}$ of other cluster, it also determine the radius of other cluster during handoff. TIBCRPH [18] shows superior performance for different number of nodes and speed when compared with some traditional routing protocols.

The protocol proposed in [19] was designed especially for highway scenarios called as cluster-based directional routing protocol (CBDRP) in which the $\mathrm{CH}$ selects one more $\mathrm{CH}$ based on moving direction of vehicle. A node in a cluster broadcasts an 'apply packet' [19] containing location of cluster, its own location and its own velocity vector, which is received by each node in cluster including the $\mathrm{CH}$. The current $\mathrm{CH}$ replies with another apply packet containing details like cluster location, its location and velocity of another node who is in center of cluster and not a $\mathrm{CH}$. If the node don't receive 'apply packet' will become $\mathrm{CH}$. CBDRP shows superior result when compare with other protocols in terms of high packet delivery ratio, minimal latency, high link stability and high packet delivery ratio [19]. The protocol named as Cluster Based Routing (CBR) is proposed in [20] in which a geographic area is divided into logical grid and each block has unique ID associated with it. CBR [20] gives preference to become $\mathrm{CH}$ to node who is close to center of grid and node who didn?t receive a message that contains location of $\mathrm{CH}$ and coordinate of its grid from $\mathrm{CH}$ and other nodes. Routing in CBR [20] is done in traditional manner via one $\mathrm{CH}$ to other $\mathrm{CH}$, but the packet forwarded across a serial grids one by one until it reaches to destination node. CBR [20] uses the optimal neighbor $\mathrm{CH}$ selection method, that selects neighbor $\mathrm{CH}$ having minimum angle between when compared with other neighbor $\mathrm{CH}$. This results in less delay in packet delivery, low average routing overhead and increase in packet delivery ratio.

The concept of Vice Cluster Head ( $\mathrm{VCH})$ is proposed in [21] in which another $\mathrm{CH}$ is present (as $\mathrm{VCH}$ ) in sudden absence of current $\mathrm{CH}$ to increase the lifetime of the cluster in network. VCHCBRP [21] is an enhancement to traditional CBRP protocol [7]. $\mathrm{VCH}$ is elected in same way as $\mathrm{CH}$ elected in CBRP [7] protocol, that broadcasts its presence by sending a notification to each node in its cluster being vice $\mathrm{CH}$. VCH-CBRP [21] is tested on average end-to-end delay, number of routing packets, normalized routing load, packets delivery fraction with increasing number of nodes. Simulation results shows that VCH-CBRP [21] has better performance than CBRP [7].

The vehicle in urban area are influence by traffic lights, when they move in the same direction close to each other forms a natural clus- 
ter as soon as the traffic lights turns green [22]. A different type of clustering technique is proposed in [22] which has two tier architecture known as Mobile Infrastructure Based VANET (MI-VANET). In this, the upper tier constitutes of buses that are communication backbone to forward data packets and lower tier is composed of ordinary cars and other vehicles. Buses are used as communication backbone because of its large overlapping radio range and they are present at fixed distance each other (as they departs at interval of 15 minutes [22]). Vehicles in lower tier are required to first register with a nearby bus for communication. Thus, when a car (source car) wants to send a message, it has to first send the message to its registered bus (source bus) via a method called MIRG (Mobile Infrastructure Registering) [22]. Here the source bus will receives the message from a lower tier node and forward the message to the higher tier nodes (i.e. destination bus). Then, the destination bus will forward the message to the destination node (destination car). MI-VANET [22] has improved the connectivity between clusters and the simulation result shows superior data delivery ratio and increase in network throughput.

Nasreddine Lagraa et al uses clustering scheme to determine the position of nodes in VANET in absence of Global Positioning System (GPS) [23]. In this, if a node receives a message from $\mathrm{CH}$ then it becomes member node, else it declares itself as first $\mathrm{CH}$ with position $(0,0)$ and considers itself as center node [23]. The distance between first $\mathrm{CH}$ and other nearby vehicle is calculated using a technique called Received Signal Strength Indication (RSSI) and using their reference the position of other nodes is calculated using trilateration method [23]. Once the positions of nodes is determined the previous selected $\mathrm{CH}$ selects two random $\mathrm{CHs}$ based on vehicles distance and mobility speed. Now, this newly selected $\mathrm{CHs}$ calculate the positions of their neighbors using the same technique of trilateration. This process is repeated for all the new nodes. Furthermore, the proposed Localization technique in VANets using Clustering (LVC) shows low Rate of Nodes with Position (RNP) when compared with GPS-free positioning MANET technique GPMAN [23].

Epidemic Routing is a technique in which each node in network forwards the replica of every received packet to each new neighbor it meets. Due to this technique the buffer of node is always filled with duplicate data packets even if no nodes are present in neighborhood, this makes high consumption of network resources and the overhead of each node is increased. So, a novel data forwarding scheme is proposes in [24] that combines autonomous clustering and Epidemic Routing for VANETs. In this, the whole cluster is considered as one virtual node that works on Store-Carry-Forward mechanism of Epidemic Routing. Only the $\mathrm{CH}$ is responsible for performing Epidemic Routing mechanism. When $\mathrm{CH}$ encounters any other cluster it forwards data packets to the cluster in which the destination node belong, and the $\mathrm{CH}$ of other cluster routes these packets to its destination. This decreases the data sending time from source to destination, less packets are stored in buffer and has low overhead. The traffic signal are used as communication backbone for routing and traffic monitoring in [25] by Venkata Manoj D et al. In this the beforehand calculated density of vehicle is send to these traffic signal. This algorithm works in such a way that, at any point of time the node is in one or other state. Thus, when a node enters in network it checks whether it is reached at Start Point or not. If yes, then the node is part of cluster formation process and if it goes in Header Selection State (HSS) it becomes CH when no reply received from neighbors and reached at maximum 'THRESHOLD point' [25]. And if reply received from neighbors, the node goes in 'Cluster Head Election State' (CH-ES) [25]. The simulation results shows better accuracy in estimating the density, increased in number of $\mathrm{CHs}$, less delay and high delivery ratio.

In [26] B. Ramakrishnan el al created a clustering model for simple highway scenario in VANET called as Simple Highway Mobility Model (SHWM). In this a clustering framework is developed for better communication among the vehicles in VANET. The algorithm can creates three types of clusters small, medium or large, depending on mobility of nodes and density. The RSU have greater processing power and hence the algorithm immediately select RSU as $\mathrm{CH}$. Else it elect $\mathrm{CH}$ to a node having less velocity. The analysis is based on SHWM model i.e. Cluster Creation Time (CCT), Cluster Head Election Time (CHET) and Cluster Head Transition Time (CHTT) for different nodes [26]. Furthermore the performance of SHWM in terms of CCT and CHET, shows CH election took place for less number of times. To increase the stability of clusters a stability-based clustering algorithm (SBCA) is proposed in [27] that uses mobility of vehicles, number of neighbors, and $\mathrm{CHs}$ duration of a node. In SBCA [27] initially the node receive an ITJ packet from $\mathrm{CH}$ (if $\mathrm{CH}$ present) or received signal strength of $\mathrm{CH}$ is higher or a node sends RTJ message to $\mathrm{CH}$ to become a part of cluster. In SBCA there are two types of $\mathrm{CHs}$ are elected, Primary $\mathrm{CH}(\mathrm{PCH})$ that is selected based on difference between velocities of neighboring vehicles and Secondary $\mathrm{CH}(\mathrm{SCH})$ which acts as a backup $\mathrm{CH}$ in case if $\mathrm{PCH}$ suddenly leaves the cluster. $\mathrm{SCH}$ is elected by $\mathrm{PCH}$ from its $\mathrm{CMs}$ having least sum of velocity difference between itself and CM. As CM do not have to generate extra packets for $\mathrm{CH}$ election it saves time and a stable clustering is achieved with minimum overhead. SBCA shows stable cluster topology, less clustering overhead and superior packet delivery ratio that improves the efficiency of SBCA.

On demand transmission power control is another cluster-based approach proposed by Fadillah Purnama Rezha et al in [28]. In this the transmission range of $\mathrm{CH}$ changes depending on the distance between $\mathrm{CH}$ and $\mathrm{CM}$, for this the $\mathrm{CH}$ keeps broadcasting its position to $\mathrm{CM}$ and calculates its distance from $\mathrm{CH}$. Upon obtaining the distance $\mathrm{CM}$ can now refer to a transmission range mapping table that is used to map the transmission range into transmission power [28]. Cluster is formed by periodically broadcasting information to update the transmission range. To predicted future distance between other vehicle and $\mathrm{CH}$ a Uniformly accelerated Motion Model is used. Simulation results shows that proposed scheme has better throughput and less transmission delay.

A data transfer scheme using autonomous clustering is proposed in [29], which is an extension of proposed protocol in [24]. A CH is continuously broadcasting MEP (cluster MEmber Packet) [29] in its cluster, when a node in another cluster listens to these packets it obtains a list of data packets from that cluster. It compares this data packet list within its own cluster and if they are new data packets it ask to the $\mathrm{CH}$ of first cluster to forward to itself. The MEP packet also contains vehicle moving direction and position with it. So, when a $\mathrm{CH}$ wish to forward data packets to another cluster it checks whether the $\mathrm{CH}$ of neighboring cluster is closer to the destination node or not and whether it is moving toward the direction of the destination node or not. Then $\mathrm{CH}$ forwards the duplicated data packets in Epidemic Routing way to $\mathrm{CH}$ of next cluster to avoid the redundant spread of data packets. This scheme shows low overhead, lowest consumed packet buffer and shortest download time from source to destination. 
One more novel algorithm is proposed to make stable clusters in [30] in which, the clusters are formed between the vehicles traveling in the same direction and the neighbors are considered at $2 \mathrm{r}-$ distance (distance to another node away from its double transmission range) called as r-neighbors [30]. The neighbors of any vehicle are classified as stable neighbors or non-stable neighbors depending on their varying threshold value. During cluster formation each vehicles has to maintain and update two sets of its 2 r-stable neighbors, one containing vehicles with higher velocity and other with lower velocity and forms a cluster of slower speed vehicles. The performance analysis of this proposed threshold based (TB) technique, is compare with the weight based (WB) and the positionbased (PB) methods for different transmission range and different velocity. Result shows that average number of cluster change is less, average cluster lifetime is high and average number of cluster formed is decreased.

A good Quality of Service (QoS) is must in VANET, thus a scheme proposed in [31] that uses Time Division Multiple Access (TDMA) to find and establish a path through clusters. In this, the cluster is formed between vehicles who have same transmission range and moving in same direction. The node can be in three modes i.e. transmitting, receiving or in $\mathrm{CH}$ mode. To select best, reliable and stable route from source to destination via $\mathrm{CH}$, the QoS metrics collects and maintains the up-to-date state information of network and finds feasible paths for a connection depending on its QoS requirements. Cluster based TDMA occurs when the $\mathrm{CH}$ allocate time slot to its members, and within this time they send QoS authenticated request to destination node and receives an unicast QoS reply. This approach gives high throughput, low packet delivery ratio and better channel utilization when compared with QoS of AODV routing protocol.

In [32] by Amal A. Eltahir el at, Universal Mobile telecommunication System (UMTS) is integrated in VANET environment, that gives stable internet connection and an extended coverage area in no coverage zone. In this approach, the vehicles are equipped with Universal Terrestrial Radio Access Network (UTRAN) and IEEE $802.11 \mathrm{p}$ interface that acts like a GN for other vehicles moving outside the UMTS coverage zone. The coverage area of UMTS cell is considered as cluster and it is a boundary of urban and rural region. The GN are selected using their received signal strength (RSS) threshold. And using Simple Additive Weighting (SAW) technique the weight of each GN is calculated and is compared with overall sum of weighted all metric values based upon RSS, available route capacity and link stability. The GN having equal weight as that of average is considered to be as $\mathrm{CH}$. This nodes then work as intermediate between vehicles in urban region and vehicles in rural region. This approach gives low packet drop ratio, better packet delivery ratio and reduce the amount of overhead.

In [33] Daxin Tian et al proposed a position-based clustering for multi-hop message dissemination for VANET environment. This uses both the proactive and reactive techniques of ad hoc routing in the multi-hop packet forwarding environment. It selects reactive approach when the nodes lie in direction of destination node, upsurge the chance of getting a shortest path. Whereas a store-carryforward scheme is used as proactive approach. Thus combining both the techniques wherever it is necessary reduces the routing control overhead while keeping high data transmitting rate.

Finally, a protocol is proposed that guarantee a stable and long lifetime clusters known as Adaptive Weighted Clustering Protocol (AWCP) [34]. As VANET have different possible configurations

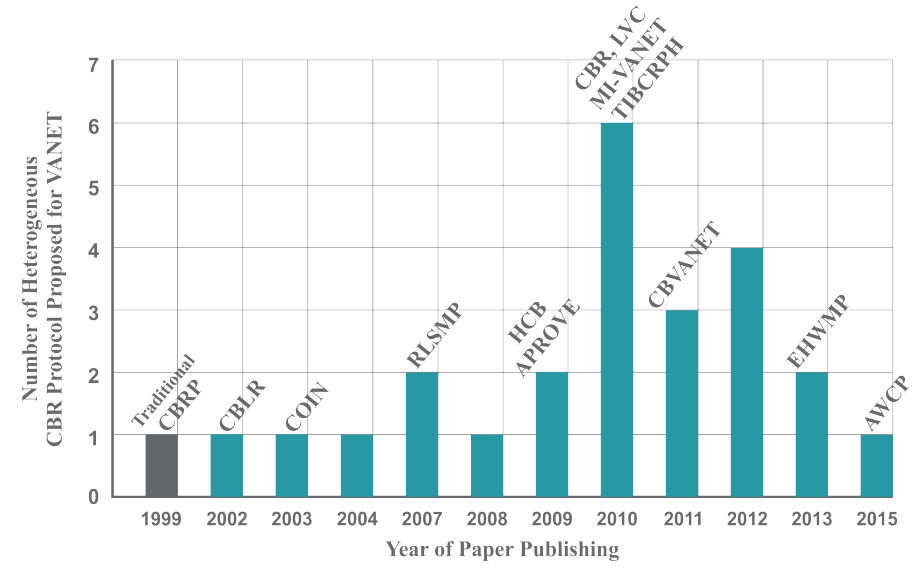

Fig. 3. Evolution of Cluster Based Technique used in VANET

a non-dominated sorted genetic algorithm (NSGA-II) is used to find the optimal values of the parameters of AWCP. The proposed AWCP uses the highway ID (number given to highway by government) and movement of vehicles moving in same direction to form a clusters. As soon as the vehicles comes in range of other vehicles, the new vehicle changes its state from UN to Cluster Head Candidate (CHC) [34]. The performance of AWCP depends on various parameter settings which eventually defines its behavior. Hence an optimization technique is used to tune these solution vector (parameter) of real variables to obtain a good QoS for AWCP. The analysis of AWCP is done on Average Cluster Lifetime, Control Packet Overhead and Packet Delivery Ratio. When AWCP is optimized using NSGA-II with most balanced setting of parameters it shows better result in terms of Hello Interval, Election Interval, $\mathrm{CH}$ Timeout Interval, Cluster Size etc.

\section{DISCUSSION}

In VANET, high mobility of vehicles leads to the constant break down of links, but using the clustering this can be fixed easily. Dividing the network into clusters can help to achieve the efficient transmission of data packets as data transmission becomes limited within the clusters. Data to other clusters can be sent via $\mathrm{CH}$ and GN nodes that increases the scalability of the network. Every method discussed in this paper, researchers have tried to improve the cluster based technique for better efficiency using different approaches.

For example, the approach used in COIN [12] creates clusters of vehicles moving in one direction which increases scalability, gives the guarantee of location awareness and decreases the overhead. Protocols like VCHCBRP [21] uses core concepts of CBRP [7] protocol, presents a different approach of selecting two CH. MI-VANET [22] presents a new concept of using bus as an intermediate node in communication between other vehicles which improves connectivity between clusters resulting in increased network throughput. Furthermore, they have proposed protocol to improve stability of cluster (SBCA [27] and [30]). They used clustering to locate vehicles in absence of GPS and in some protocols they make use of epidemic routing to upsurge the broadcasting capabilities in VANET.

The protocols discussed in paper are proposed to mitigate the imperfection of CBRP. Though theses protocols guarantee the quality of service, but they fail to solve the problems of VANET. Besides, no author suggests or proposed scheme (except in [34]) that uses an 
Table 1. Techniques and Approaches Used in Proposed Protocols

\begin{tabular}{|c|c|c|c|c|}
\hline $\begin{array}{l}\text { Proposed Protocol Name } \\
\text { \& Reference }\end{array}$ & Particular Technique/Method Used & Cluster Formation & Cluster Head Election & $\begin{array}{l}\text { Mobility } \\
\text { Scenario }\end{array}$ \\
\hline $\begin{array}{l}\text { Cluster Based Routing } \\
\text { Protocol (CBRP) [7] }\end{array}$ & - NA - & $\begin{array}{l}\text { To become part of clus- } \\
\text { ter a UN sends HMs to } \\
\text { already build cluster or } \\
\text { forms a new cluster by } \\
\text { declaring itself as } \mathrm{CH} \text {. }\end{array}$ & $\begin{array}{l}\text { Node having } \\
\text { among lowest ID } \\
\text { elected as } \mathrm{CH}\end{array}$ & - NA - \\
\hline $\begin{array}{l}\text { Cluster Based Location } \\
\text { Routing (CBLR) [10] }\end{array}$ & - NA - & $\begin{array}{l}\text { An UN forms cluster by } \\
\text { sending HMs to other } \\
\text { nodes and UN change } \\
\text { its state to } \mathrm{MN}, \mathrm{CH} \text { or } \\
\text { GN. }\end{array}$ & $\begin{array}{l}\text { Same as elected in CBRP } \\
\text { [7] }\end{array}$ & $\begin{array}{l}\text { Two circular } \\
\text { lanes having } \\
\text { opposite di- } \\
\text { rection }\end{array}$ \\
\hline $\begin{array}{l}\text { Clustering for Open IVC } \\
\text { Networks (COIN) [12] }\end{array}$ & - NA - & $\begin{array}{l}\text { Nodes moving in same } \\
\text { direction forms cluster. }\end{array}$ & $\begin{array}{l}\text { Node having highest } \\
\text { weight elected as } \mathrm{CH} \text {. }\end{array}$ & Highway \\
\hline $\begin{array}{l}\text { Improving Broadcasting } \\
\text { Performance by Clustering } \\
\text { with Stability for Inter- } \\
\text { Vehicle Communication } \\
\text { [14] }\end{array}$ & Rebroadcasting of packets is done. & $\begin{array}{l}\text { The nodes who receives } \\
\text { broadcasted HMs cre- } \\
\text { ates a dynamic list of its } \\
\text { neighbors to form clus- } \\
\text { ter. }\end{array}$ & $\begin{array}{l}\text { Based on same moving di- } \\
\text { rection, having a lower ID } \\
\text { than other node or from } \\
\text { leadership duration. }\end{array}$ & $\begin{array}{l}\text { Highway } \\
\text { and City } \\
\text { Based } \\
\text { Scenario. }\end{array}$ \\
\hline $\begin{array}{l}\text { Affinity PROpagation } \\
\text { for VEhiclar networks } \\
(\text { APROVE) [17] }\end{array}$ & $\begin{array}{l}\text { Uses Affinity Propagation (AP) for } \\
\text { fast cluster formation. }\end{array}$ & $\begin{array}{l}\text { Using minimum dis- } \\
\text { tance and relative } \\
\text { velocity of } \mathrm{CH} \text { and its } \\
\text { members. }\end{array}$ & $\begin{array}{l}\text { Election of } \mathrm{CH} \text { is done pe- } \\
\text { riodically, by using affinity } \\
\text { propagation. }\end{array}$ & $\begin{array}{l}\text { Highway } \\
\text { Scenarios }\end{array}$ \\
\hline \begin{tabular}{lr} 
Traffic & \multicolumn{2}{c}{ Infrastructure } \\
Based Cluster & Routing \\
Protocol with & Handoff \\
$($ TIBCRPH) [18] &
\end{tabular} & $\begin{array}{l}\text { Handoff metric technique is used to } \\
\text { determine the radius of other cluster } \\
\text { during handoff. }\end{array}$ & - NA - & $\begin{array}{l}\text { Using handoff metric } \\
\text { when a node changes its } \\
\text { position from one cluster } \\
\text { to another. }\end{array}$ & $\begin{array}{l}\text { City Based } \\
\text { Scenario }\end{array}$ \\
\hline $\begin{array}{lr}\text { Cluster-Based } & \text { Direc- } \\
\text { tional Routing } & \text { Protocol } \\
(\mathrm{CBDRP})[19] & \end{array}$ & $\begin{array}{l}\text { No such particular method is used but } \\
\mathrm{CH} \text { of one cluster selects another } \mathrm{CH} \\
\text { based on moving direction of vehicle. }\end{array}$ & $\begin{array}{l}\text { Vehicles coming only } \\
\text { from one direction are } \\
\text { part of a cluster. }\end{array}$ & $\begin{array}{l}\text { Node at center of cluster } \\
\text { and didn?t receive apply } \\
\text { packet from current } \mathrm{CH} \text {. }\end{array}$ & $\begin{array}{l}\text { Straight } \\
\text { Highway }\end{array}$ \\
\hline $\begin{array}{l}\text { Cluster Based Routing } \\
(\mathrm{CBR})[20]\end{array}$ & $\begin{array}{l}\text { To select best neighbor } \mathrm{CH} \text {, CBR } \\
\text { uses optimal neighbor } \mathrm{CH} \text { selection } \\
\text { method to calculate minimum angle } \\
\text { between two or more } \mathrm{CH} \text {. }\end{array}$ & $\begin{array}{l}\text { The nodes inside logical } \\
\text { four square grid denotes } \\
\text { a cluster. }\end{array}$ & $\begin{array}{l}\text { Node present at center of } \\
\text { grid and who didn't re- } \\
\text { ceive location of CH I\& } \\
\text { coordinate of its grid. }\end{array}$ & $\begin{array}{l}\text { City Based } \\
\text { Scenario }\end{array}$ \\
\hline $\begin{array}{l}\text { Vice Cluster Head Clus- } \\
\text { ter Based Routing Proto- } \\
\text { col (VCHCBRP) [21] }\end{array}$ & $\begin{array}{l}\text { Self-healing scheme is used by elect- } \\
\text { ing a VCH to maintain the lifetime of } \\
\text { cluster in sudden absence of current } \\
\mathrm{CH} \text {. }\end{array}$ & Same as CBRP [7] & $\begin{array}{l}\mathrm{VCH} \text { is elected in same } \\
\text { way as elected in CBRP } \\
\text { [7] }\end{array}$ & $\begin{array}{l}\text { Random } \\
\text { Way-Point }\end{array}$ \\
\hline \begin{tabular}{ll} 
Mobile & \multicolumn{2}{c}{ Infrastructure } \\
Based $\quad$ VANET (MI- \\
VANET) [22]
\end{tabular} & $\begin{array}{l}\text { MIRG is used to calculate the con- } \\
\text { nection expected time of nearby bus } \\
\text { and choose longer expected connec- } \\
\text { tion time and shorter distance to reg- } \\
\text { ister. Whereas MIRT (Mobile Infras- } \\
\text { tructure Routing) [22] is used for rout- } \\
\text { ing packets between buses. }\end{array}$ & $\begin{array}{l}\text { Vehicle forms a natu- } \\
\text { ral cluster as soon as } \\
\text { the traffic lights turns } \\
\text { green. }\end{array}$ & $\begin{array}{l}\text { The registered buses can } \\
\text { be considered as } \mathrm{CH} \text {, since } \\
\text { all the messages are send } \\
\text { and received via buses. }\end{array}$ & $\begin{array}{l}\text { Urban } \\
\text { VANETs } \\
\text { (City Based } \\
\text { Scenario) }\end{array}$ \\
\hline $\begin{array}{l}\text { Localization technique in } \\
\text { VANets using Clustering } \\
\text { (LVC) [23] }\end{array}$ & $\begin{array}{l}\text { RSSI and Trilateration technique is } \\
\text { used for establishment of relative po- } \\
\text { sitions of nearby nodes. }\end{array}$ & $\begin{array}{l}\text { A center node forms } \\
\text { a cluster by determin- } \\
\text { ing positions of other } \\
\text { nodes. }\end{array}$ & $\begin{array}{l}\text { Node elects itself as } \mathrm{CH} \text { if } \\
\text { no message received from } \\
\text { current } \mathrm{CH} \text {. }\end{array}$ & - NA - \\
\hline $\begin{array}{l}\text { Data forwarding scheme } \\
\text { using Epidemic Routing } \\
\text { and Autonomous Cluster- } \\
\text { ing [24] }\end{array}$ & $\begin{array}{l}\text { Combination of Autonomous cluster- } \\
\text { ing and Epidemic Routing is used to } \\
\text { reduce packet storage in buffer and to } \\
\text { lower the overhead. }\end{array}$ & $\begin{array}{l}\mathrm{CH} \text { broadcasts MEP } \\
\text { (MEmber Packet) to its } \\
\mathrm{CM} \text { to maintain tree } \\
\text { structure. }\end{array}$ & $\begin{array}{l}\text { The node who receives } \\
\text { MEP maintains the role of } \\
\mathrm{CH} \text {. }\end{array}$ & $\begin{array}{l}\text { City Based } \\
\text { Scenario }\end{array}$ \\
\hline $\begin{array}{l}\text { Clustering scheme for } \\
\text { routing and traffic moni- } \\
\text { toring in VANET [25]. }\end{array}$ & $\begin{array}{l}\text { The optimal length of cluster is calcu- } \\
\text { lated from TH-DISTANCE [25], used } \\
\text { to } \mathrm{CH} \text { election and cluster formation. }\end{array}$ & $\begin{array}{l}\text { As soon as the node } \\
\text { reaches at Start Point, } \\
\text { the node is part of clus- } \\
\text { ter formation process. }\end{array}$ & $\begin{array}{l}\text { When the node goes in } \\
\text { Header Selection State } \\
\text { (HSS) it becomes } \mathrm{CH} \text {. }\end{array}$ & $\begin{array}{l}\text { Car follow- } \\
\text { ing with } \\
\text { overtaking }\end{array}$ \\
\hline $\begin{array}{l}\text { Simple Highway Mobility } \\
\text { Model(SHWM) [26]. }\end{array}$ & $\begin{array}{l}\text { Involves dynamic clustering that cre- } \\
\text { ate small, medium or large clusters de- } \\
\text { pending on nodes motion \& density. }\end{array}$ & $\begin{array}{l}\text { Clusters are formed de- } \\
\text { pending on mobility of } \\
\text { nodes and density. }\end{array}$ & $\begin{array}{l}\text { Select RSU as } \mathrm{CH} \text { if it is } \\
\text { detected if not selection is } \\
\text { based on less velocity. }\end{array}$ & $\begin{array}{l}\text { Highway } \\
\text { Scenario }\end{array}$ \\
\hline
\end{tabular}




\begin{tabular}{|c|c|c|c|c|}
\hline $\begin{array}{l}\text { Stability-Based Clus- } \\
\text { tering Algorithm } \\
\text { (SBCA) [27] }\end{array}$ & $\begin{array}{l}\text { No such technique is used but for } \\
\mathrm{CH} \text { selection least sum of velocity } \\
\text { difference between PCH and CM } \\
\text { is calculated. }\end{array}$ & $\begin{array}{l}\mathrm{CH} \text { replies with } \\
\text { acknowledgement of } \\
\text { ITJ or RTJ message } \\
\text { of node to form } \\
\text { cluster. }\end{array}$ & $\begin{array}{l}\text { PCH is elected based } \\
\text { on difference between } \\
\text { speed of neighbor ve- } \\
\text { hicle. And SCH is se- } \\
\text { lected by PCH. }\end{array}$ & $\begin{array}{l}\text { Highway } \\
\text { Model. }\end{array}$ \\
\hline $\begin{array}{l}\text { Clustering using adap- } \\
\text { tive transmission power } \\
\text { scheme [28]. }\end{array}$ & $\begin{array}{l}\text { Future distance to } \mathrm{CH} \text { is predicted } \\
\text { via a Uniformly accelerated Mo- } \\
\text { tion Model [28]. }\end{array}$ & $\begin{array}{l}\text { Information to up- } \\
\text { date transmission } \\
\text { range is broadcasted } \\
\text { periodically. }\end{array}$ & $\begin{array}{l}\mathrm{CH} \text { is elected in same } \\
\text { way same as elected in } \\
\text { CBRP [7]. }\end{array}$ & $\begin{array}{l}\text { Highway } \\
\text { Scenario }\end{array}$ \\
\hline $\begin{array}{l}\text { Data forwarding in } \mathrm{Au}- \\
\text { tonomous Cluster [29]. }\end{array}$ & $\begin{array}{l}\text { Combination of Autonomous } \\
\text { clustering and Epidemic Routing } \\
\text { is used to forward data packets. }\end{array}$ & $\begin{array}{l}\mathrm{CH} \text { broadcasts MEP } \\
\text { to its } \mathrm{CM} \text { to maintain } \\
\text { tree structure. }\end{array}$ & $\begin{array}{l}\text { The node who receives } \\
\text { MEP maintains the role } \\
\text { of } \mathrm{CH} \text {. }\end{array}$ & $7 \times 7$ grid \\
\hline $\begin{array}{l}\text { A novel algorithm to } \\
\text { form stable clusters in } \\
\text { VANET [30] }\end{array}$ & $\begin{array}{l}\text { A technique called neighborhood } \\
\text { relationship of a node is pro- } \\
\text { posed to identify neighbors at } 2 \mathrm{r}- \\
\text { distance. }\end{array}$ & $\begin{array}{l}\text { Between vehicles go- } \\
\text { ing in same direction } \\
\text { and neighbors at } 2 \mathrm{r}- \\
\text { distance. }\end{array}$ & $\begin{array}{l}\text { Based on stable neigh- } \\
\text { bors, less distance \& } \\
\text { average closer speed } \\
\text { with its neighbors. }\end{array}$ & $\begin{array}{l}\text { Highway } \\
\text { Scenario }\end{array}$ \\
\hline $\begin{array}{l}\text { TDMA-based QoS } \\
\text { routing for clusters in } \\
\text { VANET [31]. }\end{array}$ & $\begin{array}{l}\text { TDMA techniques is used to send } \\
\text { data packets in particular time in- } \\
\text { terval from one cluster to another. }\end{array}$ & $\begin{array}{l}\text { Vehicles moving in } \\
\text { same direction and } \\
\text { have same transmis- } \\
\text { sion range. }\end{array}$ & $\begin{array}{l}\text { If no message is re- } \\
\text { ceived within a time pe- } \\
\text { riod node selected itself } \\
\text { as } \mathrm{CH} \text {. }\end{array}$ & $\begin{array}{l}\text { Mobility } \\
\text { Model: } \\
500 \mathrm{~m} \quad \mathrm{x} \\
500 \mathrm{~m}\end{array}$ \\
\hline $\begin{array}{l}\text { Enhanced Hybrid Wire- } \\
\text { less Mesh Protocol (E- } \\
\text { HWMP) [32] }\end{array}$ & $\begin{array}{l}\text { UMTS is used to connect vehi- } \\
\text { cles to the internet. And SAW } \\
\text { techniques is used to calculated } \\
\text { weight of GN. }\end{array}$ & $\begin{array}{l}\text { UMTS cell edges is } \\
\text { considered to be as } \\
\text { one cluster. }\end{array}$ & $\begin{array}{l}\mathrm{GN} \text { is } \mathrm{CH} \text { if it having } \\
\text { weight same as average } \\
\text { weight of all GN. }\end{array}$ & $\begin{array}{l}\text { Highway } \\
\text { Scenario }\end{array}$ \\
\hline $\begin{array}{l}\begin{array}{l}\text { Clustering } \\
\text { information } \\
\text { dissem- } \\
\text { ination in } \\
{[33] .}\end{array} \\
{[3 A N E T}\end{array}$ & $\begin{array}{l}\text { Learning algorithm is based on } \\
\text { the Hebb neural network is used } \\
\text { to form cluster and choose a } \mathrm{CH} \text {. }\end{array}$ & $\begin{array}{l}\text { Clusters are formed } \\
\text { from learning algo- } \\
\text { rithm which is based } \\
\text { on the Hebb neural } \\
\text { network. }\end{array}$ & $\begin{array}{l}\mathrm{CH} \text { is chosen by the } \\
\text { unsupervised learning } \\
\text { scheme, using gradient } \\
\text { optimization process. }\end{array}$ & $\begin{array}{l}\text { Highway, } \\
\text { Straight } \\
\text { Road, } \\
\text { Road with } \\
90 \& \quad 45 \\
\text { Curve }\end{array}$ \\
\hline $\begin{array}{lr}\text { Adaptive } & \text { Weighted } \\
\text { Clustering } & \text { Protocol } \\
(\text { AWCP) [34] } & \end{array}$ & $\begin{array}{l}\text { NSGA-II is used to find the op- } \\
\text { timal values of the parameters of } \\
\text { AWCP }\end{array}$ & $\begin{array}{l}\text { Highway ID and } \\
\text { vehicles moving in } \\
\text { same direction used } \\
\text { to form clusters. }\end{array}$ & $\begin{array}{l}\text { Average minimum dis- } \\
\text { tance and slow speed of } \\
\text { all neighbors vehicles. }\end{array}$ & $\begin{array}{l}\text { Real High- } \\
\text { way from } \\
\text { Open } \\
\text { Street Map }\end{array}$ \\
\hline
\end{tabular}

artificial intelligence technique like fuzzy logic or particle swarming optimization to address the major issues of VANET network. Therefore, finding the best setting of optimization technique to configuring these protocols is a major issue and a future work. However, several optimization algorithms have been proposed recently like discussed in [34] but there is still more to explore.

Lastly, we presented a table that gives a brief idea of what techniques are used in proposed approaches, how clusters are formed and how $\mathrm{CH}$ are elected. It also shows that how a single clustering technique is used in different ways. Furthermore, a time line graph in Fig.3 shows the evolution of cluster based technique used in VANET and in which year how many protocols were proposed.

\section{CONCLUSION}

In this paper, we have presented a survey of heterogeneous approaches for cluster based routing protocol. A deep investigation is done from traditional cluster based protocol to different approaches proposed using clustering technique for VANET. Each and every proposed scheme utilizes the clustering technique and shows better result than other. We can conclude that a lot of work had been done by using the traditional clustering technique, many protocols have been proposed and now these protocols must be optimized using optimization techniques like swarm or ant optimization for effective performance.

\section{REFERENCES}

[1] D.A. Rosen, F.J. Mammano, and R. Favout. An electronic route-guidance system for highway vehicles. Vehicular Technology, IEEE Transactions on, 19(1):143-152, Feb 1970.

[2] A.M. Vegni and V. Loscri. A survey on vehicular social networks. Communications Surveys Tutorials, IEEE, 17(4):23972419, Fourthquarter 2015.

[3] The Wikipedia website : [Online]. Vehicular Ad Hoc Network. https://en.wikipedia.org/wiki/Vehicular ${ }_{a} d_{h}$ oc ${ }_{n}$ etwork.

[4] S. Singh and S. Agrawal. Vanet routing protocols: Issues and challenges. In Engineering and Computational Sciences (RAECS), 2014 Recent Advances in, pages 1-5, March 2014.

[5] S. Allal and S. Boudjit. Geocast routing protocols for vanets: Survey and guidelines. In Innovative Mobile and Internet Services in Ubiquitous Computing (IMIS), 2012 Sixth International Conference on, pages 323-328, July 2012.

[6] Ching chuan Chiang, Hsiao-Kuang Wu, Winston Liu, and Mario Gerla. Routing in clustered multihop, mobile wireless networks with fading channel. In IEEE SICON?97, In proceedings of the IEEE Singapore International Conference on Network, pages 197-211, 1997.

[7] Y.C. Tay Mingliang Jiang, Jinyang Li. IETF [Online] Draft : Cluster Based Routing Protocol (CBRP) Functional Specification 
Internet Draft, 14 August 1999. https://tools.ietf.org/html/draftietf-manet-cbrp-spec-01.

[8] B. Das, R. Sivakumar, and V. Bharghavan. Routing in ad hoc networks using a spine. In Computer Communications and Networks, 1997. Proceedings., Sixth International Conference on, pages 34-39, Sep 1997.

[9] P. Krishna, N. H. Vaidya, M. Chatterjee, and D. K. Pradhan. A cluster-based approach for routing in dynamic networks. SIGCOMM Comput. Commun. Rev., 27(2):49-64, April 1997.

[10] R.A. Santos, R.M. Edwards, and N.L. Seed. Using the clusterbased location routing (cblr) algorithm for exchanging information on a motorway. In Mobile and Wireless Communications Network, 2002. 4th International Workshop on, pages 212-216, 2002.

[11] R.A. Santos, R.M. Edwards, A. Edwards, and D. Belis. A novel cluster-based location routing algorithm for intervehicular communication. In Personal, Indoor and Mobile Radio Communications, 2004. PIMRC 2004. 15th IEEE International Symposium on, volume 2, pages 1032-1036 Vol.2, Sept 2004.

[12] J. Blum, A. Eskandarian, and L. Hoffman. Mobility management in IVC networks. In Intelligent Vehicles Symposium, 2003. Proceedings. IEEE, pages 150-155, June 2003.

[13] H. Saleet and O. Basir. Location-based message aggregation in vehicular ad hoc networks. In Globecom Workshops, 2007 IEEE, pages 1-7, Nov 2007.

[14] Peng Fan. Improving broadcasting performance by clustering with stability for inter-vehicle communication. In Vehicular Technology Conference, 2007. VTC2007-Spring. IEEE 65th, pages 2491-2495, April 2007.

[15] Seyed Amin Hosseini Seno and masoumeh ghahramani. A new approach cbrp based resource information management in manets. International Journal of Computer Science and Network Security, 8(5):301-308, May 2008.

[16] Yang Xia, Chai Kiat Yeo, and Bu Sung Lee. Hierarchical cluster based routing for highly mobile heterogeneous manet. In Network and Service Security, 2009. N2S ?09. International Conference on, pages 1-6, June 2009.

[17] C. Shea, Behnam Hassanabadi, and S. Valaee. Mobility-based clustering in vanets using affinity propagation. In Global Telecommunications Conference, 2009. GLOBECOM 2009. IEEE, pages 1-6, Nov 2009.

[18] Tiecheng Wang and Gang Wang. TIBCRPH: Traffic infrastructure based cluster routing protocol with handoff in vanet. In Wireless and Optical Communications Conference (WOCC), 2010 19th Annual, pages 1-5, May 2010.

[19] Tao Song, Weiwei Xia, Tiecheng Song, and Lianfeng Shen. A cluster-based directional routing protocol in vanet. In Communication Technology (ICCT), 2010 12th IEEE International Conference on, pages 1172-1175, Nov 2010.

[20] Yuyi Luo,Wei Zhang, and Yangqing Hu. A new cluster based routing protocol for VANET. In Networks Security Wireless Communications and Trusted Computing (NSWCTC), 2010 Second International Conference on, volume 1, pages 176-180, April 2010.

[21] M.B. Yassein and N. Hijazi. Improvement on cluster based routing protocol by using vice cluster head. In Next Generation Mobile Applications, Services and Technologies (NGMAST), 2010 Fourth International Conference on, pages 137-141, July 2010.
[22] Jie Luo, Xinxing Gu, Tong Zhao, and Wei Yan. MI-VANET: A new mobile infrastructure based VANETarchitecture for urban environment. In Vehicular Technology Conference Fall (VTC 2010Fall), 2010 IEEE 72nd, pages 1-5, Sept 2010.

[23] Nasreddine Lagraa, Mohamed Bachir Yagoubi, Sarah Benkouider, et al. Localization technique in VANETs using clustering (LVC). International Journal of Computer Science Issues (IJCSI), 7(9):10-16, April 2010.

[24] S. Teshima, T. Ohta, E. Kohno, and Y. Kakuda. A data transfer scheme using autonomous clustering in vanets environment. In Autonomous Decentralized Systems (ISADS), 2011 10th International Symposium on, pages 477-482, March 2011.

[25] M.D. Venkata, M.M.M. Pai, R.M. Pai, and J. Mouzna. Traffic monitoring and routing in VANETs - A cluster based approach. In ITS Telecommunications (ITST), 2011 11th International Conference on, pages 27-32, Aug 2011.

[26] B Ramakrishnan, RS Rajesh, and RS Shaji. Cbvanet: A cluster based vehicular adhoc network model for simple highway communication. International Journal of Advanced Networking and Applications, 2(04):755-761, 2010.

[27] A. Ahizoune and A. Hafid. A new stability based clustering algorithm (SBCA) for vanets. In Local Computer Networks Workshops (LCN Workshops), 2012 IEEE 37th Conference on, pages 843-847, Oct 2012.

[28] F.P. Rezha, T.S. Siadari, and Soo Young Shin. Adaptive transmission power in cluster-based routing vanet. In Communications (APCC), 2012 18th Asia-Pacific Conference on, pages 539-543, Oct 2012.

[29] Y. Ohta, T. Ohta, and Y. Kakuda. An autonomous clustering based data transfer scheme using positions and moving direction of vehicles for vanets. In Wireless Communications and Networking Conference (WCNC), 2012 IEEE, pages 2900-2904, April 2012.

[30] Zaydoun Y Rawashdeh and Syed Masud Mahmud. A novel algorithm to form stable clusters in vehicular ad hoc networks on highways. EURASIP Journal onWireless Communications and Networking, 2012(1):1-13, 2012.

[31] A.A. Mu'azu, Low Tang Jung, I.A. Lawal, and P.A. Shah. A QoS approach for cluster-based routing in vanets using tdma scheme. In ICT Convergence (ICTC), 2013 International Conference on, pages 212-217, Oct 2013.

[32] A.A. Eltahir, R.A. Saeed, and M.A. Alawi. An enhanced hybrid wireless mesh protocol (E-HWMP) protocol for multihop vehicular communications. In Computing, Electrical and Electronics Engineering (ICCEEE), 2013 International Conference on, pages 1-8, Aug 2013.

[33] Daxin Tian, Yunpeng Wang, Haiying Xia, and Fengtian Cai. Clustering multi-hop information dissemination method in vehicular ad hoc networks. Intelligent Transport Systems, IET, 7(4):464472, December 2013.

[34] M. Hadded, R. Zagrouba, A. Laouiti, P. Muhlethaler, and L.A. Saidane. A multi-objective genetic algorithm-based adaptive weighted clustering protocol in vanet. In Evolutionary Computation (CEC), 2015 IEEE Congress on, pages 994-1002, May 2015. 